\title{
Comparative Effectiveness Research: Are The Methods Being Used Correctly?
}

Paula Andrade*, Tatiana Dilla and José A Sacristán

Medical Department, Lilly, Avenida de la Industria, Madrid, Spain

*Corresponding author: Paula Andrade, Health Outcomes Scientist, Medical Department, Lilly, Avenida de la Industria, 30,28108 Alcobendas, Madrid, Spain, Tel: +34 9162333 16; Fax: +34 9166352 31; E-mail: andrade_paula@lilly.com

Received date: June 02, 2017; Accepted date: June 19, 2017; Published date: June 26, 2017

Copyright: (c) 2017 Andrade P, et al. This is an open-access article distributed under the terms of the Creative Commons Attribution License, which permits unrestricted use, distribution, and reproduction in any medium, provided the original author and source are credited.

\begin{abstract}
Rationale, aims and objectives: Comparative Effectiveness Research (CER) seeks to identify what health care interventions work best for improving health at both the individual and population level. The objective of this study was to determine whether published comparative effectiveness research studies adhere to accepted methodological principles.
\end{abstract}

Methods: Structured literature search of CER articles published in high-impact general medicine journals between 2009 and 2015, and assessment of their adherence to five methodological principles.

Results: 93 articles were retrieved from the search and 40 articles were finally selected. All of the studies included active comparators, $35 \%$ of the studies did not evaluate safety, $97 \%$ did not evaluate costs, $95 \%$ of the studies did not included patient perspectives, and $60 \%$ did not use any procedure to determine the heterogeneity of the response.

Conclusion: The sample of CER papers examined did not meet the recommended requisites for this type of studies. Our findings suggest that the majority of CER studies may not be useful to guide physicians, purchasers, and policy makers to make informed decisions that improve health care at both the individual and population levels.

Keywords: Health care; CER studies; Clinical setting; Heterogeneity; Medical interventions; Placebo; Safety analysis; Quality journals; Health outcomes

\section{Introduction}

Comparative Effectiveness Research (CER) studies compare the relative effectiveness of different medical interventions in the diagnosis or treatment of a specific disease. In recent years, CER has garnered the advocacy and support of the US Institute of Medicine (IOM), numerous government healthcare agencies, and international organizations [1-3]. According to the formal definition by the IOM, CER is "the generation and synthesis of evidence that compares the benefits and harms of alternative methods to prevent, diagnose, treat, and monitor or improve the delivery of care". CER has the potential of providing information "to assist consumers, clinicians, purchasers, and policy makers to make informed decisions that will improve health care at both the individual and population levels" [4]. The two main characteristic aspects of CER studies are the comparison of active treatments (active comparator studies) rather than the comparison of an active treatment with a placebo or the absence of a comparator, and the evaluation of the effects of interventions in a real-world setting. CER studies should contrast alternatives that are already used in the clinical setting but for which effectiveness data are not available or are insufficient to demonstrate superiority over other treatments [5-7]. The comparison interventions in CER may include medications, procedures, medical and assistive devices and technologies, behavioural change strategies, and delivery systems.
Apart from these two characteristics, the definition of CER suggests that the study of effectiveness cannot be the only objective of the programmes. Aspects such as safety and cost are relevant elements as well [7]. Additionally, CER studies should not only assess the best treatment option for the average patient but also analyse the best option for each individual patient [8]. Since the available evidence may be incomplete or does not apply to certain patient populations, such as children or the elderly, organisations such as the Patient-Centred Outcomes Research Institute (PCORI) promotes CER studies to generate new evidence in different health care interventions and across a broad range of medical conditions and patient populations $[9,10]$.

Despite the extensive amount of CER literature, little is known about the characteristics of published CER studies and how they fit into the CER concept. Therefore, the goal of this work was to characterize relevant CER studies to analyse if they met comparative effectiveness major objectives.

\section{Methods}

The MEDLINE and EMBASE databases were searched using the search terms "Comparative AND effectiveness [Title] AND ("2009/05/18" [PDat]: "2015/05/18" [PDat])". All original articles with a title containing the words "comparative" and "effectiveness" were selected. The search was limited to articles published between 2009 and 2015 in the 10 general-medicine journals with the highest 2013 impact factor (NEJM, IF: 54.42; Lancet, IF: 39.20; JAMA-J Am Med Assoc, IF: 30.38; Brit Med J, IF: 16.37; Ann Intern Med, IF: 16.10; PLOS Med, IF: 14.00; Arch Intern Med, IF: 13.24; BMC Med, IF: 7.27; Cochrane DB 
Page 2 of 6

Syst Rev, IF: 5.93). After the search and the elimination of duplicates, 93 articles were obtained. These articles were manually reviewed to eliminate Opinions and Editorials. Finally, 40 articles met the requirements. These articles were double-checked by two independent investigators to extract the relevant data included in this analysis. Disagreement was resolved by consensus.

The following variables were analysed in each of the selected articles: use and type of treatment (active or placebo), safety as primary or secondary objective, cost assessment, inclusion of Patient Reported Outcomes (PROs), analysis of the heterogeneity in the response, type of intervention evaluated, study design, therapeutic area, and funding source. The variables were analysed using descriptive statistics.

\section{Results}

Study characteristics of the sample of 40 CER publications included in this review are presented in Table 1. Of these, 25 were comparative studies of medicines and 15 of other types of medical intervention. Independently of the intervention evaluated, and in relation to the most important features of CER studies, we found that active comparators were used in all of the studies, and $20 \%$ of them also used a placebo. $62.5 \%$ described comparisons between medications, while $37.5 \%$ studied other types of medical interventions (e.g., behavioural, surgical devices, diagnostic strategies).

\begin{tabular}{|c|c|c|c|}
\hline & Medications (N=25) & Other interventions ( $N=15$ ) & Total $(\mathrm{N}=40)$ \\
\hline Reference number & [29-53] & [54-68] & - \\
\hline \multicolumn{4}{|l|}{ Active vs. inactive comparators } \\
\hline Active & 25 & 15 & $40(100 \%)$ \\
\hline Placebo & 8 & 0 & $8(20 \%)$ \\
\hline \multicolumn{4}{|l|}{ Type of comparator } \\
\hline Different drugs & 24 & 2 & $26(65 \%)$ \\
\hline Non-pharmacological interventions & 3 & 10 & $13(33 \%)$ \\
\hline Different strategies & 1 & 4 & $5(13 \%)$ \\
\hline \multicolumn{4}{|l|}{ Safety (adverse effects) } \\
\hline Yes (primary or secondary) & 17 & 9 & $26(65 \%)$ \\
\hline No & 8 & 6 & $14(35 \%)$ \\
\hline \multicolumn{4}{|l|}{ Cost analysis } \\
\hline Yes & 1 & 0 & $1(3 \%)$ \\
\hline No & 24 & 15 & $39(97 \%)$ \\
\hline \multicolumn{4}{|l|}{ Inclusion of PROs } \\
\hline Yes & 2 & 0 & $2(5 \%)$ \\
\hline No & 23 & 15 & $38(95 \%)$ \\
\hline \multicolumn{4}{|l|}{ Assess the heterogeneity in the response } \\
\hline Yes & 10 & 6 & $16(40 \%)$ \\
\hline Subgroup analysis & 9 & 5 & 14 \\
\hline Propensity score & 4 & 4 & 8 \\
\hline Risk adjustment & 0 & 0 & 0 \\
\hline No & 15 & 9 & $24(60 \%)$ \\
\hline \multicolumn{4}{|l|}{ Study design } \\
\hline Randomised clinical trials (RCT) & 2 & 4 & $6(15 \%)$ \\
\hline Observational (prospective or retrospective) & 4 & 5 & $9(23 \%)$ \\
\hline Meta-analysis/Systematic review & 17 & 5 & $22(55 \%)$ \\
\hline Model & 2 & 1 & $3(8 \%)$ \\
\hline
\end{tabular}




\begin{tabular}{|l|l|l|l|}
\hline Therapeutic area & 1 & 0 & 1 \\
\hline Pain & 7 & 6 & 13 \\
\hline Cardiovascular & 4 & 0 & 4 \\
\hline Infectious & 1 & 0 & 1 \\
\hline Arthritis & 4 & 3 & 7 \\
\hline Diabetes & 1 & 0 & 1 \\
\hline Glaucoma & 1 & 0 & 1 \\
\hline Osteoporosis & 1 & 0 & 1 \\
\hline Chronic obstructive pulmonary disease & 1 & 1 & 3 \\
\hline Central nervous system & 2 & 1 & 5 \\
\hline Oncology & 2 & 3 & 3 \\
\hline Others & 1 & 2 & $10(25 \%)$ \\
\hline Funding & & & \\
\hline Public & 18 & 12 & $30(75 \%)$ \\
\hline Private & 7 & 3 & \\
\hline
\end{tabular}

Table 1: Characteristics of the CER studies analysed.

The safety of the interventions was evaluated in $65 \%$ of the studies as primary or secondary objective. Cost analyses were performed in $3 \%$ of the papers. Respect to the "patient centricity" of the studies, PROs were included in $5 \%$ of the publications and $40 \%$ of them used some procedure to determine the heterogeneity of the response.

The most common CERs were meta-analyses or systematic reviews (55\%), followed by observational studies (23\%) and Randomized Clinical Trials (RCTs) (15\%). With regard to the source of funding, $75 \%$ of the publications received public support. In our sample, the most represented medical field is the cardiovascular area, followed by diabetes.

\section{Discussion}

The results of this study show that the CER articles analysed did not meet the criteria commonly accepted for CER studies. Although all papers included active-drug comparators, 20\% also included comparisons with placebo. As previously stated, comparison groups in CER studies should reflect clinical choices in real world practice. The comparison of interventions with a clinically meaningful alternative is usually a better choice from a methodological perspective than the comparison with an untreated group. The option of "no treatment" may not meet usual standards of care where multiple therapeutic options are available and should be limited only to certain clinical situations. Our finding about the use of placebo in CER studies can be partially explained by the methodology used in many of the studies analysed, which were meta-analyses and systematic reviews that included Randomized Clinical Trials (RTCs) with different treatment comparison arms including placebo.

Safety analysis was included in $65 \%$ of the publications. Since the ultimate goal of CER is to provide decision makers with accurate and scientifically-rigorous information for comparing alternative clinical options, CER studies should systematically include not just the effectiveness but also an evaluation of safety. We observe an imbalance in the measuring of the treatment efficacy over treatment risk and safety. Although the methodology to assess the safety of medical interventions is less standardized than the assessment of their efficacy, we believe than CER studies should focus on the assessment of the risk-benefit of the compared interventions [11].

Regarding cost comparisons, an economic analysis of the alternatives was performed in only $3 \%$ of the studies. Although CER should allow making clinical decisions in an environment of limited resources, this is a controversial point with which not all stakeholders agree [12]. According to the detractors, if economic considerations were included, there would be many interventions with small but positive health benefits that would not be compensated by the additional cost and that, therefore, would not be recommended. However, as some medical organizations have recently highlighted, performing Cost-Effectiveness Analysis (CEA) is important to compare and contextualize the price of any intervention [12-14].

With regard to patients' perspectives, $5 \%$ of the analysed studies collected PROs. A fully informative CER should incorporate patients' perspectives standardised in the form of PROs [15]. Patients' perspectives can generate valuable information for clinical health professionals in their decision-making processes [16-18]. The importance of incorporating PROs has been emphasised by regulatory (i.e., the U.S. Food and Drug Administration) and National Health Agencies (i.e., the U.S. National Institutes of Health) [19] as well as by organisations such as PCORI, with the objective of developing patientcentred medicine [3]. However, our analysis highlights the fact that few studies take patient perspectives into consideration.

Regarding the assessment of the heterogeneity of the response in patient subgroups, the goal of CER is to identify interventions that 
work best in specific subtypes of patients. The majority of the studies included in this study (60\%) did not use any procedures directed at identifying uniqueness in the response of patient subgroups. In order to increase the generalizability of the results, CER studies usually use wide selection criteria. However, it is increasingly evident that although most therapeutic decisions rely on information obtained based on the average patient, the one-size-fits-all approach is not the ideal to optimise healthcare as it does not cover the singularities of the individual patient $[20,21]$. CER programmes should include patientoriented research methods to assess the responses in individuals and subgroups with the objective of "particularising" the results [8,22-24]. Therefore, current research falls short of the ambitious goal of improving "health care at both the individual and population levels", as stated in the CER definition.

Although pragmatic RCTs could be considered as the gold standard for the evaluation of CER, other designs such as observational studies or mixed treatment comparisons (MTCs) [25], systematic reviews, meta-analyses, or decision analysis models [26] are frequently used. In our review, most of the CER studies were systematic reviews or metaanalyses (55\%), followed by observational studies $(23 \%)$ and clinical trials (15\%) (Of which half were pragmatic RCTs). The low number of pragmatic RCTs agrees with the results of other reviews [27,28]. The implementation of CER based on pragmatic RCTs and observational studies should be encouraged.

This study has a number of limitations. The most important one is the potential information bias caused by the inclusion of only highimpact-factor general medicine journals. Our search selected only those articles that included the words "comparative" and "effectiveness" in the title. However, the biases introduced by the selection of journals and articles support our hypothesis because by including CER studies of higher quality, one would expect that they would better comply with the theoretical requirements of these studies. It is foreseeable that the identified problems will be even greater with less stringent criteria, including lower quality journals and articles that do not include the CER concept in their titles.

\section{Conclusion}

Our study shows that most of the CERs analysed did not adhere to the five basic requirements that these studies should fulfil. Among other issues, they often included comparisons with placebo, did not evaluate the safety or the cost of the interventions, did not usually include PROS, and did not take into account heterogeneity in the response. In our opinion, it is necessary to encourage true CER studies primarily based on pragmatic RCTs or observational studies carried out under conditions of actual clinical practise. Only in this way it will be possible to achieve higher quality healthcare systems capable of improving the health outcomes of individual patients.

\section{References}

1. Iglehart JK (2009) Prioritizing comparative-effectiveness research-IOM recommendations. N Engl J Med 361: 325-328.

2. Stafford RS, Wagner TH, Lavori PW (2009) New, but not improved? Incorporating comparative-effectiveness information into FDA labeling. N Engl J Med 361: 1230-1233.

3. Methodology Committee of the Patient-Centered Outcomes Research Institute (2012) Methodological standards and patient-centeredness in comparative effectiveness research: the PCORI perspective. J Am Med Assoc 307: 1636-1640
4. Sox HC (2010) Defining comparative effectiveness research: the importance of getting it right. Med Care 48: S7-S8.

5. Sox HC, Goodman SN (2012) The methods of comparative effectiveness research. Ann Rev Public Health 33: 425-445.

6. Sox HC, Greenfield S (2009) Comparative effectiveness research: a report from the Institute of Medicine. Ann Intern Med 151: 203-205.

7. Sox HC, Helfand M, Grimshaw J, Dickersin K, Tovey D, et al. (2010) Comparative effectiveness research: challenges for medical journals. Croat Med J 51: 191-194.

8. Slutsky JR, Clancy CM (2010) Patient-centered comparative effectiveness research: essential for high-quality care. Arch Intern Med 170: 403-404.

9. Conway PH, Clancy C (2010) Charting a path from comparative effectiveness funding to improved patient-centered health care. J Am Med Assoc 303: 985-986.

10. Selby JV, Beal AC, Frank L (2012) The Patient-Centered Outcomes Research Institute (PCORI) national priorities for research and initial research agenda. J Am Med Assoc 307: 1583-1584.

11. Strom BL (2007) Methodologic challenges to studying patient safety and comparative effectiveness. Med Care 45: S13-S15.

12. American College of Physicians (2008) Information on cost-effectiveness: an essential product of a national comparative effectiveness program. Ann Intern Med 148: 956-961.

13. Neumann PJ, Sanders GD (2017) Cost-Effectiveness Analysis 2.0. N Engl J Med 376: 203-205.

14. Francis MH (2012) Beyond "safe and effective": the role of the federal government in supporting and disseminating comparative-effectiveness research. Ann Health Law 21: 329-382.

15. Ahmed S, Berzon RA, Revicki DA, Lenderking WR, Moinpour CM, et al. (2012) The use of Patient-Reported Outcomes (PRO) within comparative effectiveness research: implications for clinical practice and health care policy. Med Care 50: 1060-1070.

16. Basch E (2010) The missing voice of patients in drug-safety reporting. $\mathrm{N}$ Engl J Med 362: 865-869.

17. Pakhomov SV, Jacobsen SJ, Chute CG, Roger VL (2008) Agreement between patient-reported symptoms and their documentation in the medical record. Am J Manag Care 14: 530-539.

18. Mullins CD, Abdulhalim AM, Lavallee DC (2012) Continuous patient engagement in comparative effectiveness research. J Am Med Assoc 307: 1587-1588.

19. Basch E, Abernethy AP, Mullins CD, Reeve BB, Smith ML, et al. (2012) Recommendations for incorporating patient-reported outcomes into clinical comparative effectiveness research in adult oncology. J Clin Oncol 30: 4249-4255.

20. Sacristan JA (2013) Patient-centered medicine and patient-oriented research: improving health outcomes for individual patients. BMC Med Inform Decis Mak 13: 6

21. Sacristan JA, Dilla T (2017) Generalizability in Pragmatic Trials. J Am Med Assoc 317: 87-88.

22. Sculpher M (2010) Reflecting heterogeneity in patient benefits: the role of subgroup analysis with comparative effectiveness. Value Health 13: S18S21.

23. Kaplan SH, Billimek J, Sorkin DH, Ngo-Metzger Q, Greenfield S (2010) Who can respond to treatment? Identifying patient characteristics related to heterogeneity of treatment effects. Med Care 48: S9-S16.

24. Velentgas P, Dreyer NA, Nourjah P, Smith SR, Torchia MM (2013) Developing a protocol for observational comparative effectiveness research: a user's guide. Rockville.

25. Eichler HG, Thomson A, Eichler I, Schneeweiss S (2015) Assessing the relative efficacy of new drugs: an emerging opportunity. Nat Rev Drug Discov 14: 443-444.

26. Meyer AM, Wheeler SB, Weinberger M, Chen RC, Carpenter WR (2014) An overview of methods for comparative effectiveness research. Semin Radiat Oncol 24: 5-13. 
27. Thorpe KE, Zwarenstein M, Oxman AD, Treweek S, Furberg CD, et al (2009) A pragmatic-explanatory continuum indicator summary (PRECIS): a tool to help trial designers. J Clin Epidemiol 62: 464-475.

28. Luce BR, Kramer JM, Goodman SN, Connor JT, Tunis S, et al. (2009) Rethinking randomized clinical trials for comparative effectiveness research: the need for transformational change. Ann Intern Med 151: 206-209.

29. Abou-Setta AM, Beaupre LA, Rashiq S, Dryden DM, Hamm MP, et al. (2011) Comparative effectiveness of pain management interventions for hip fracture: a systematic review. Ann Intern Med 155: 234-245.

30. Adam SS, McDuffie JR, Lachiewicz PF, Ortel TL, Williams JW (2013) Comparative effectiveness of new oral anticoagulants and standard thromboprophylaxis in patients having total hip or knee replacement: a systematic review. Ann Intern Med 159: 275-284.

31. Adam SS, McDuffie JR, Ortel TL, Williams JW (2012) Comparative effectiveness of warfarin and new oral anticoagulants for the management of atrial fibrillation and venous thromboembolism: a systematic review. Ann Intern Med 157: 796-807.

32. Baker WL, Coleman CI, Kluger J, Reinhart KM, Talati R, et al. (2009) Systematic review: comparative effectiveness of angiotensin-converting enzyme inhibitors or angiotensin II-receptor blockers for ischemic heart disease. Ann Intern Med 151: 861-871.

33. Bannuru RR, Schmid CH, Kent DM, Vaysbrot EE, Wong JB, et al. (2015) Comparative effectiveness of pharmacologic interventions for knee osteoarthritis: a systematic review and network meta-analysis. Ann Intern Med 162: 46-54

34. Bennett WL, Maruthur NM, Singh S, Segal JB, Wilson LM, et al. (2011) Comparative effectiveness and safety of medications for type 2 diabetes: an update including new drugs and 2-drug combinations. Ann Intern Med 154: 602-613.

35. Boland MV, Ervin AM, Friedman DS, Jampel HD, Hawkins BS, et al. (2013) Comparative effectiveness of treatments for open-angle glaucoma: a systematic review for the U.S. Preventive Services Task Force. Ann Intern Med 158: 271-279.

36. Chou R, Hartung D, Rahman B, Wasson N, Cottrell EB, et al. (2013) Comparative effectiveness of antiviral treatment for hepatitis $\mathrm{C}$ virus infection in adults: a systematic review. Ann Intern Med 158: 114-123.

37. Crandall CJ, Newberry SJ, Diamant A, Lim YW, Gellad WF, et al. (2014) Comparative effectiveness of pharmacologic treatments to prevent fractures: an updated systematic review. Ann Intern Med 161: 711-723.

38. Drekonja DM, Butler M, MacDonald R, Bliss D, Filice GA, et al. (2011) Comparative effectiveness of Clostridium difficile treatments: a systematic review. Ann Intern Med 155: 839-847.

39. Fretheim A, Odgaard-Jensen J, Brors O, Madsen S, Njolstad I, et al. (2012) Comparative effectiveness of antihypertensive medication for primary prevention of cardiovascular disease: systematic review and multiple treatments meta-analysis. BMC Med 10: 33.

40. Griebeler ML, Morey-Vargas OL, Brito JP, Tsapas A, Wang Z, et al. (2014) Pharmacologic interventions for painful diabetic neuropathy: An umbrella systematic review and comparative effectiveness network metaanalysis. Ann Intern Med 161: 639-649.

41. Hartling L, Abou-Setta AM, Dursun S, Mousavi SS, Pasichnyk D, et al. (2012) Antipsychotics in adults with schizophrenia: comparative effectiveness of first-generation versus second-generation medications: a systematic review and meta-analysis. Ann Intern Med 157: 498-511.

42. Maher AR, Maglione M, Bagley S, Suttorp M, Hu JH, et al. (2011) Efficacy and comparative effectiveness of atypical antipsychotic medications for off-label uses in adults: a systematic review and meta-analysis. J Am Med Assoc 306: 1359-1369.

43. Nelson HD, Fu R, Griffin JC, Nygren P, Smith ME, et al. (2009) Systematic review: comparative effectiveness of medications to reduce risk for primary breast cancer. Ann Intern Med 151: 703-15.

44. Sharma M, Ansari MT, Abou-Setta AM, Soares-Weiser K, Ooi TC, et al (2009) Systematic review: comparative effectiveness and harms of combination therapy and monotherapy for dyslipidemia. Ann Intern Med 151: 622-630.
45. Wu HY, Huang JW, Lin HJ, Liao WC, Peng YS, et al. (2013) Comparative effectiveness of renin-angiotensin system blockers and other antihypertensive drugs in patients with diabetes: systematic review and bayesian network meta-analysis. BMJ.

46. Gagne JJ, Choudhry NK, Kesselheim AS, Polinski JM, Hutchins D, et al. (2014) Comparative effectiveness of generic and brand-name statins on patient outcomes: a cohort study. Ann Intern Med 161: 400-407.

47. Gershon A, Croxford R, To T, Stanbrook MB, Upshur R, et al. (2011) Comparison of inhaled long-acting beta-agonist and anticholinergic effectiveness in older patients with chronic obstructive pulmonary disease: a cohort study. Ann Intern Med 154: 583-592.

48. Parker ED, Margolis KL, Trower NK, Magid DJ, Tavel HM, et al. (2012) Comparative effectiveness of 2 beta-blockers in hypertensive patients. Arch Intern Med 172: 1406-1412.

49. Roumie CL, Hung AM, Greevy RA, Grijalva CG, Liu X, et al. (2012) Comparative effectiveness of sulfonylurea and metformin monotherapy on cardiovascular events in type 2 diabetes mellitus: a cohort study. Ann Intern Med 157: 601-610.

50. Smith SS, McCarthy DE, Japuntich SJ, Christiansen B, Piper ME, et al. (2009) Comparative effectiveness of 5 smoking cessation pharmacotherapies in primary care clinics. Arch Intern Med 169: 2148-2155.

51. Rini BI, Escudier B, Tomczak P, Kaprin A, Szczylik C, et al. (2011) Comparative effectiveness of axitinib versus sorafenib in advanced renal cell carcinoma (AXIS): a randomised phase 3 trial. Lancet 378: 1931-1939.

52. Alistar SS, Grant PM, Bendavid E (2014) Comparative effectiveness and cost-effectiveness of antiretroviral therapy and pre-exposure prophylaxis for HIV prevention in South Africa. BMC Med 12: 46.

53. Bendavid E, Brandeau ML, Wood R, Owens DK (2010) Comparative effectiveness of HIV testing and treatment in highly endemic regions. Arch Intern Med 170: 1347-1354.

54. Bruening W, Fontanarosa J, Tipton K, Treadwell JR, Launders J, et al. (2010) Systematic review: comparative effectiveness of core-needle and open surgical biopsy to diagnose breast lesions. Ann Intern Med 152: 238-246.

55. Chou R, Dana T, Bougatsos C, Blazina I, Starmer AJ, et al. (2013) Pressure ulcer risk assessment and prevention: a systematic comparative effectiveness review. Ann Intern Med 159: 28-38.

56. Smith ME, Totten A, Hickam DH, Fu R, Wasson N, et al. (2013) Pressure ulcer treatment strategies: a systematic comparative effectiveness review. Ann Intern Med 159: 39-50.

57. Terasawa T, Balk EM, Chung M, Garlitski AC, Alsheikh-Ali AA, et al. (2009) Systematic review: comparative effectiveness of radiofrequency catheter ablation for atrial fibrillation. Ann Intern Med 151: 191-202.

58. Yeh HC, Brown TT, Maruthur N, Ranasinghe P, Berger Z, et al. (2012) Comparative effectiveness and safety of methods of insulin delivery and glucose monitoring for diabetes mellitus: a systematic review and metaanalysis. Ann Intern Med 157: 336-347.

59. Hlatky MA, Boothroyd DB, Baker L, Kazi DS, Solomon MD, et al. (2013) Comparative effectiveness of multivessel coronary bypass surgery and multivessel percutaneous coronary intervention: a cohort study. Ann Intern Med 158: 727-734.

60. Ionescu-Ittu R, Abrahamowicz M, Jackevicius CA, Essebag V, Eisenberg MJ, et al. (2012) Comparative effectiveness of rhythm control vs rate control drug treatment effect on mortality in patients with atrial fibrillation. Arch Intern Med 172: 997-1004.

61. Kerlikowske K, Hubbard RA, Miglioretti DL, Geller BM, Yankaskas BC et al. (2011) Comparative effectiveness of digital versus film-screen mammography in community practice in the United States: a cohort study. Ann Intern Med 155: 493-502.

62. Masoudi FA, Mi X, Curtis LH, Peterson PN, Curtis JP, et al. (2014) Comparative effectiveness of cardiac resynchronization therapy with an implantable cardioverter-defibrillator versus defibrillator therapy alone: a cohort study. Ann Intern Med 160: 603-611. 
63. Weintraub WS, Grau-Sepulveda MV, Weiss JM, O'Brien SM, Peterson ED et al. (2012) Comparative effectiveness of revascularization strategies. N Engl J Med 366: 1467-1476.

64. Appel LJ, Clark JM, Yeh HC, Wang N, Coughlin JW, et al. (2011) Comparative effectiveness of weight-loss interventions in clinical practice. N Engl J Med 365: 1959-1968.

65. Chung B, Ong M, Ettner SL, Jones F, Gilmore J, et al. (2014) 12-month outcomes of community engagement versus technical assistance to implement depression collaborative care: a partnered, cluster, randomized, comparative effectiveness trial. Ann Intern Med 161: S23S34.
66. Naik AD, Palmer N, Petersen NJ, Street RL, Rao R, et al. (2011) Comparative effectiveness of goal setting in diabetes mellitus group clinics: randomized clinical trial. Arch Intern Med 171: 453-459.

67. Sperl-Hillen J, Beaton S, Fernandes O, Worley AV, Vazquez-Benitez G, et al. (2011) Comparative effectiveness of patient education methods for type 2 diabetes: a randomized controlled trial. Arch Intern Med 171: 2001-2010.

68. Gulati R, Gore JL, Etzioni R (2013) Comparative effectiveness of alternative prostate-specific antigeb-based prostrate cancer screeming strategies: model estimates of potential benefits and harms. Ann Intern Med 158: 145-153. 